\title{
Energy efficient building envelope using waste PET in concrete
}

\author{
Gitanjali Thakur ${ }^{1}$, Mohamad Asalam ${ }^{1}$, and Mohammed El Ganaoui ${ }^{2}$ \\ ${ }^{1}$ Department of Civil Engineering, Teerthankar Mahaveer University, Moradabad, India \\ ${ }^{2}$ University of Lorraine, France
}

\begin{abstract}
One of the major environmental threat in the world today is the increased production of plastic and its usage. The inept plastic waste management system with regard to its recycling and energy recovery in the developing countries creates a global threat as a major land and water body pollutant. However, its durability, thermal properties, and chemical resistance make plastics an alternate choice as a building material. This study investigates the use of plastic in concrete mixture with an objective to improve the thermal performance of the building. The shredded plastic fibers from plastic bottles (polyethylene terephthalate, PET) were used as a partial weight replacement $(2.5 \%, 5 \%$, and $7.5 \%$ ) of coarse aggregate in concrete blocks. The cubes were cast using the Indian standards (IS 456) and the essential tests were performed. Additionally, experiments were designed to investigate the change in the thermal conductivity of the concrete block due to the varying amount of plastic. It was found that the use of PETs affected the compressive strength and also decreased the thermal conductivity of the concrete blocks. The experimental results suggest that PETs can be used in the construction of energyefficient building to handle the environmental concerns because of its abundance.
\end{abstract}

\section{Introduction}

The building sector has major impact on the quality of environment, as it consumes $40 \%$ of the total energy, $50 \%$ of the total extracted materials and $36 \%$ of the total $\mathrm{CO} 2$ emissions globally [1]. This amount of energy used and related emission will potentially increase due to the various provisions of increasing number of adequate housing in developing countries. It is therefore necessary to take steps for new construction projects from a mitigation perspective for efficient use of energy, natural resources and materials. A major portion of building energy is consumed in providing comfortable and healthy environment for its occupant through heating, air-conditioning and ventilation [2]. The environment inside a building depends largely on how the exchange of heat, moisture and wind takes place between the building envelope and the outside climate. Therefore, new building construction provides best opportunity for the implementation of an improvised building envelope which in turn can help in reducing the building energy usage.

In order to integrate sustainable development with building sector several attempts have been made to use natural or recycled materials having insulation properties in the construction of energy efficient building envelope [3]. In this regard plastic wastes makes an excellent choice as it decreases environmental pollution and it also helps in saving the energy used in recycling and production processes [4]. Furthermore, the properties of plastic like its durability, chemical resistance and low thermal conductivity reinforces its popularity as a building material [5]. This approach can be significantly useful for the developing countries as it benefits them environmentally as well as economically. Among all the available plastic types Polyethylene Terephthalate (PET) is one of the most widely used plastics because of its high dielectric and insulating properties [3]. In spite of the above-mentioned advantages of plastics it is mostly used as a secondary raw material in building construction. Only a few studies have been conducted to investigate the variation in mechanical properties of concrete using plastic as a primary raw material along with cement, sand and aggregate [5,6,7].

This work investigates the use of PET (shredded plastic water bottles) as one of the primary building material in concrete mix. The coarse aggregate in a concrete mix was partially replaced by plastic and its effect on the heat transfer capacity of the concrete mix was studied. The obtained results show that it has the potential to reduce the energy required for heating and cooling of the buildings. It can help in mitigating the environmental impacts due to inadequate disposal and recycling of plastics in the developing countries. The use of plastic in building concrete also decreases the dead load which will help in reducing the cost

\footnotetext{
Corresponding author: gitanjali.thakur90@gmail.com
} 
associated. Additionally, the water repellent nature of plastic results in desirable workability at lower water cement ratio leading to the reduced water consumption in construction. The next section of the paper presents the methodology followed to conduct the study.

\section{Methdology}

To carry out the study the following materials were used:

Coarse Aggregates: The natural aggregate size ranging between $12.5 \mathrm{~mm}$ - $20 \mathrm{~mm}$ were used having a bulk density of $2.44 \mathrm{~kg} / \mathrm{m}^{3}$.

Fine aggregates (Sand): The natural sand obtained having maximum size of $2.36 \mathrm{~mm}$ to $4.75 \mathrm{~mm}$ was used having a density of $1.5 \mathrm{~kg} / \mathrm{m}^{3}$

Cement: Portland Pozzolana Cement (PPC) was used having a specific gravity of about 3.1 .

Water: water used for mixing and curing was free from of impurities.

Plastic: The discarded plastic water bottles were shredded into rectangular, triangular shape, size varying from $10 \mathrm{~mm}$ to $20 \mathrm{~mm}$ as shown in figure1 having a density of $1.38 \mathrm{~g} / \mathrm{cm}^{3}$.

\subsection{Concrete Specimen}

All the materials mentioned above were cast in the form of cubes using the mold with a dimension of 150 $\mathrm{mm} * 150 \mathrm{~mm} * 150 \mathrm{~mm}$ as shown in figure1. Four types of concrete samples named A, B, C, D were prepared by mixing the aggregate, sand and cement in the volume ratio of $3: 1.5: 1$. Sample A was prepared without plastic whereas B, C, D were prepared through weight replacement of coarse aggregate by $2.5 \%, 5 \%$ and $7.5 \%$ as shown in Table 1. PET was used to replace the coarse aggregate considering the fact that the thermal conductivity of aggregates is highest among all constituents of the concrete mix [8].

The workability of concrete mix was estimated by performing slump cone test and the casting was done. In total 52 cubes were cast: 9 of each (A, B, C, D) for compressive strength testing at the age of 7,14 , and 28 days, 4 cubes of each sample were cast for conducting the heat flow experiments. The cubes were dried and kept for curing. The mixing, compaction and casting was done in accordance with IS456:2000.

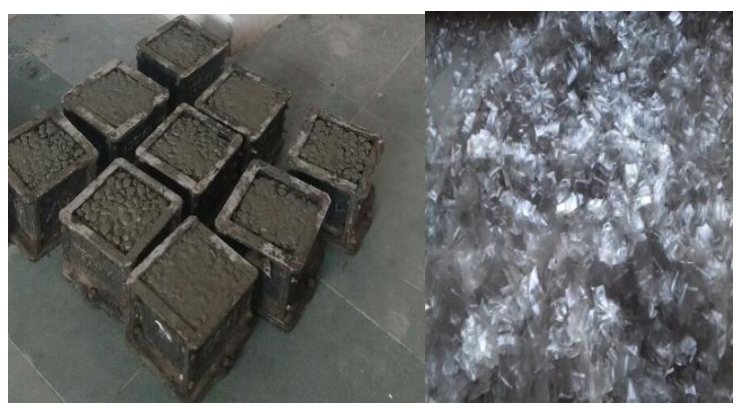

\subsubsection{Compressive strength test}

The 9 cubes of each sample were divided into three sets and each set was kept for the curing duration of 7,14 and 28 days respectively. On the completion of curing days cubes were taken and left out for at room temperature for 24 hours. The compressive strength test was performed in the Compressive Testing Machine (CTM). In the machine, the maximum load at which the crack appeared on the block was recorded. The test was repeated for 3 blocks at each curing age, the average value of the three was used as the load value which the block can resist without failure. The compressive strength of the block was obtained by dividing the average load by the surface area. The test was repeated for all the 36 blocks.

\subsubsection{Estimation of thermal conductivity}

In order to investigate the one-dimensional heat flow in concrete blocks with varying PET percentage the following arrangement was made: A heat generating coil was sandwiched between the two similar concrete block such that one face of each block was heated using the coil and the rise in temperature of the other face was recorded as shown in figure1.The blocks used for the experiment were cured for 7 days and were weighed before testing to understand the effect the volumetric density on thermal conductivity. The quantity of heat supplied to the blocks was calculated by using equation 1 , the voltage and current flowing into the heating element was measured using an Ammeter and Voltmeter as shown in figure 1. The heat flow was measured using four thermocouples (TC1, TC2, TC3, TC4). TC1, TC4 were placed at cold faces, and TC2, TC3 were placed at the hot faces as seen in figure 1. The cubes were covered using thick thermocol sheets to minimize the losses due to convection and radiation.

Table 1. Composition of concrete block samples

\begin{tabular}{ccccc} 
Blocks & \multicolumn{4}{c}{ Materials } \\
\hline & $\begin{array}{c}\text { Cement } \\
(\mathrm{kg})\end{array}$ & $\begin{array}{c}\text { Fine } \\
\text { aggregate }(\mathrm{kg})\end{array}$ & $\begin{array}{c}\text { Coarse } \\
\text { aggregate } \\
(\mathrm{Kg})\end{array}$ & $\begin{array}{c}\text { Plastic } \\
(\mathrm{g})\end{array}$ \\
\hline A & 1.90 & 1.47 & 4.418 & 0 \\
\hline B & 1.90 & 1.47 & 4.30 & 63.5 \\
\hline C & 1.90 & 1.47 & 4.19 & 127 \\
\hline D & 1.90 & 1.47 & 4.08 & 190
\end{tabular}

Fig. 1. Concrete cubes with shredded plastic 


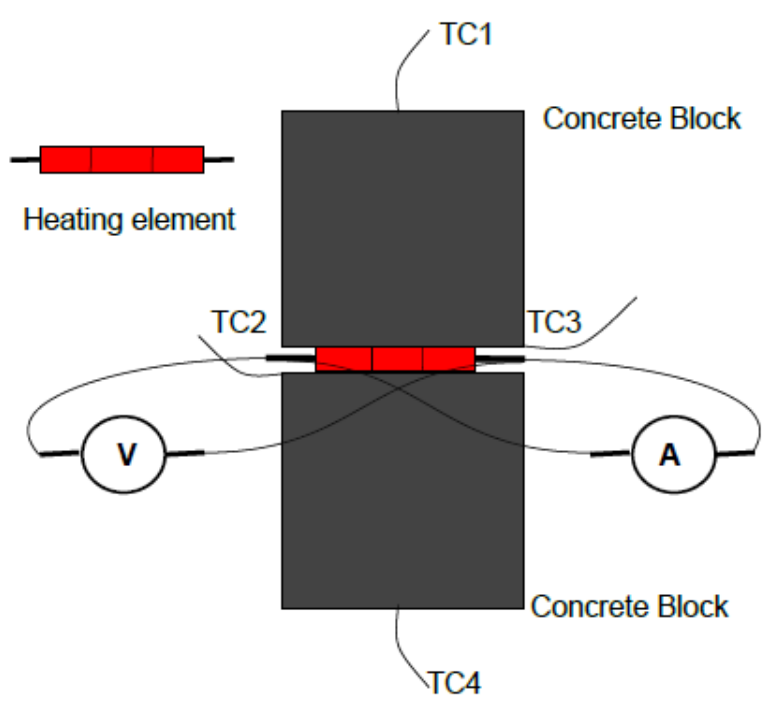

Fig. 2. Block diagram of the experimental set-up for calculating thermal conductivity

The Fourier equation of one dimensional conduction was used for the calculation of thermal conductivity mentioned in equation 2 . In order to calculate the thermal conductivity of the top block, the temperature readings of thermocouple 1 (TC1) \& 3(TC3) were recorded at every 10 minutes. Similarly, the reading of TC2 \& TC4 were recorded for the bottom blocks. The initial reading of TC1, TC2, TC3 and TC4 were $35^{\circ} \mathrm{C}$. The heating element was kept on before the readings of TC3 and TC2 reached to $110^{\circ} \mathrm{C}$. After the heating element was turned off the readings of TC2 \& TC3 started to decrease and the readings of TC1 \& TC4 kept on increasing. The readings were taken until the temperature variation was almost constant. The time at which the two consecutive readings of TC 1 and TC4 were invariant, the setup was considered to be in the steady state and equation 2 was used for the calculation.of thermal conductivity(K). The same procedure was repeated two times for each sample and the average value of $\mathrm{K}$ was estimated.

$$
Q=I * V * T
$$

Where, I is the current (A), V is the voltage (V) and T is the time (s).

$$
Q=K * A * T *\left(\frac{t_{2}-t_{1}}{l}\right)
$$

Where, $K$ is the thermal conductivity $(\mathrm{W} /(\mathrm{m} . \mathrm{K})), A$ is the area of the block $\left(\mathrm{m}^{2}\right), t_{1}$ and $t_{2}$ are the temperatures of the two opposite faces with thermocouple $\left({ }^{\circ} \mathrm{C}\right)$ and $l$ is the sample length $(\mathrm{m}) . T$ is the time for attaining steady state.

\section{Results and discussion}

The slump values obtained during the slump cone test of the four samples is given in table 2 .

Table 2. Slump values for concrete mix

\begin{tabular}{cc}
\hline Sample & Slump Values (mm) \\
\hline A & 14 \\
\hline B & 16 \\
\hline C & 19 \\
\hline D & 21 \\
\hline
\end{tabular}

As anticipated the workability of the concrete mix increases with increasing the amount of waste plastic as the w/c ratio was kept constant for all the samples. The hydrophobic nature of the plastic helped in attaining the desired workability at relatively lower $\mathrm{w} / \mathrm{c}$ ratio of 0.48 in comparison with the conventional concrete. The results of the compressive strength test show that there is an evident decrease in the compressive strength of the concrete with increasing percentage of plastic at each curing age. It is due to the fact that shredded plastic has smooth surface which acts as a water repellant so it restricts the entrance of water in the voids which is necessary for cement hydration to gain strength.

As stated by Pezzi et.al [6] the increase in the percentage of PET makes the bonds between cement and plastic very weak and the contact becomes more irregular resulting in a wide of number of voids responsible for the detoriation of the mechanical properties. The effect of this anomaly increases by increasing plastic percentage, therefore the compressive strength decreases as shown in figure 2 .

As shown in the graph that the value of compressive strength for sample $\mathrm{C}$ and $\mathrm{D}$ is less than $20 \mathrm{MPa}$ therefore, these cannot be used as M20 concrete. Nevertheless, sample $\mathrm{C}$ can be used as light weight concrete as its strength after 28 days of curing is greater than $17 \mathrm{MPa}$. During the CTM testing it was observed that the time interval between the crack appearance and complete failure of the blocks was increasing with increase in the plastic percentage. This behavior shows the decrease in brittleness of concrete by the usage of plastic. As discussed by Ismail et.al[5] the plastic fibers have potential to increase the tensile strength of concrete by filling the numerous flaws and micro-cracks existing in the concrete.

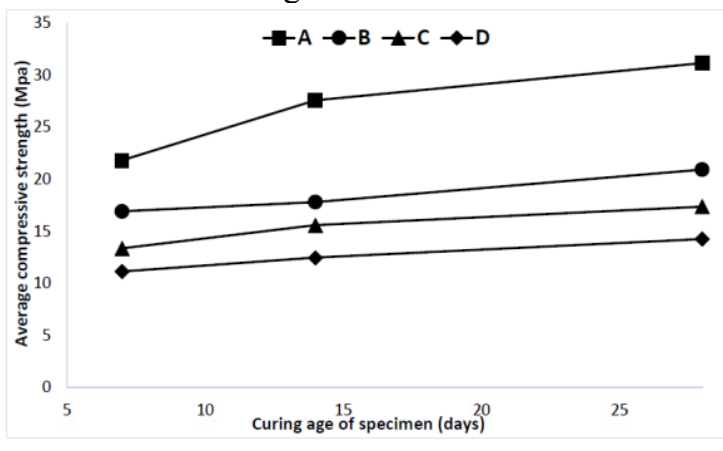

Fig. 3. Compressive strength of the concrete samples 
In order to examine the heat conduction in all the four samples the graph between time and temperature for thermocouple 1 has been plotted as shown in figure 3 . It can be observed from the graph that the rate of heat transfer in sample A is highest followed by B, C and $D$ respectively. Furthermore, it can be seen that the increase in temperature is almost constant $\left(1-2^{\circ} \mathrm{C}\right)$ after 90. Therefore, the system is in steady state and the heat conduction becomes the function of the measurement point coordinate, which is kept identical for all the samples as shown in figure 2. From the figure it is also inferred that the variation of temperature in the initial phase is non linear for sample B, C and D in comparison with sample. The reason could be the complex internal structure of the plastic polymers by absorbing heat as verified by Kim et al. [7]. In order to evaluate the thermal performance of samples critically more number of tests should be conducted with varying temperature

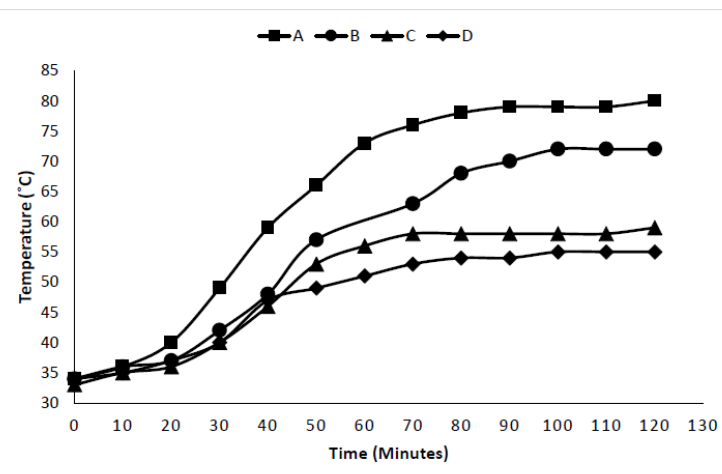

Fig. 4. Readings of thermocouple 1 w.r.t time

Table 3. Calculated Thermal Conductivity (W/m.K)

\begin{tabular}{cc}
\hline Sample & $\begin{array}{c}\text { Thermal } \\
\text { conductivity(W/m.K) }\end{array}$ \\
\hline $\mathrm{A}$ & 1.80 \\
\hline $\mathrm{B}$ & 1.38 \\
\hline $\mathrm{C}$ & 1.15 \\
\hline $\mathrm{D}$ & 0.97 \\
\hline
\end{tabular}

The estimated value of $\mathrm{K}$ for each sample is shown in table 2 , it is observed that the value of $\mathrm{K}$ is decreasing with increase in the plastic percentage. It is because of the disordered intermolecular structure of plastic fibers which decreases the rate of heat transfer. In fact, the thermal conductivity of solids depends on many factors such as density, molecular structure, porosity and moisture content [8]. As mentioned earlier due to the usage of plastic fibers, the size and number of voids in the concrete mix increases which results into decrease in density as shown in figure 4 . The lower value of $\mathrm{K}$ implies that the thermal conductivity of air filled voids are much lesser than the voids filled with concrete and water.

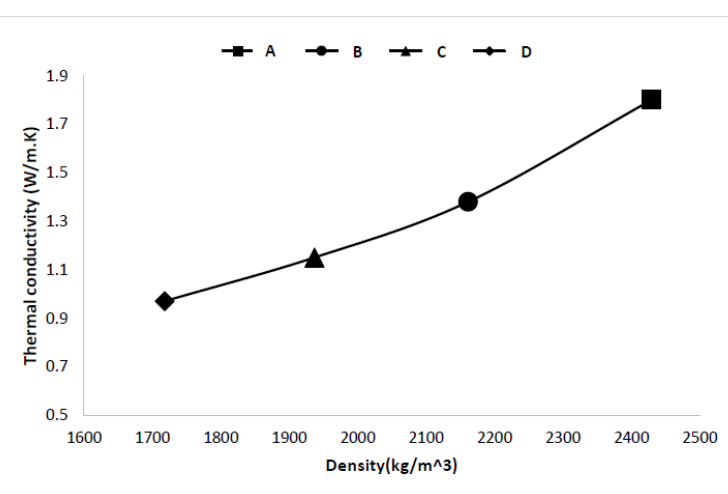

Fig. 5. Plot showing the variation of density and thermal conductivity sample blocks

As stated by Kim et.al [7] the thermal conductivity of concrete is also a function of water cement ratio therefore it will be useful if experiment will be conducted for more samples by varying curing duration and water cement ratio. The outcomes presented above demonstrates that waste plastic concrete mix can be used as a light weight concrete without high end technology at low cost.

\section{Conclusion}

Sustainability being the priority of the construction sector, the obtained results of the study acknowledge the use of plastic as a energy efficient building material. The use of 5\% PET decrease the volumetric density by $20 \%$ and the thermal conductivity by $36 \%$. Therefore, the use of waste plastic will reduce the use of natural raw material in building construction and, will allow considerable energy saving by improving the thermal performance of the buildings during their lifetime. In future work experiments can be performed using different type of waste plastic with varying size and its effect on different properties of concrete can be investigated to integrate resource efficiency and sustainability with the building sector.

\section{References}

1. A. Ruuska, \& T. Häkkinen. Material efficiency of building construction. Buildings, 4(3), 266-29, (2014).

2. An assessment of energy technologies and research opportunities (2015).

3. F. Asdrubali, F. D'Alessandro, \& S. Schiavoni. A review of unconventional sustainable building insulation materials. Sustainable Materials and Technologies, 4, 1-17, (2015).

4. F. Intini, \& S. Kühtz. Recycling in buildings : an LCA case study of a thermal insulation panel made of polyester fiber, recycled from postconsumer PET bottles. The International Journal of Life Cycle Assessment, 16(4), 306-315, (2011).

5. Z. Z. Ismail, \& E. A. Al-Hashmi. Use of waste plastic in concrete mixture as aggregate 
replacement. Waste Management, 28(11), 20412047, (2008).

6. L. Pezzi, P.A. De Luca, D. Vuono, F. Chiappetta, \& A. Nastro. Concrete products with waste's plastic material (bottle, glass, plate). In Materials Science Forum, 514, 1753. Trans Tech Publications, (2006).

7. K. H. Kim, S. E. Jeon, J. K. Kim, \& S. Yang. An experimental study on thermal conductivity of concrete. Cement and Concrete Research, 33(3), 363-371, (2003)

8. J. K. Appiah, V.N. Berko-Boateng, \& T. A. Tagbor. Use of waste plastic materials for road construction in Ghana. Case studies in construction materials, 6, 1-7, (2017). 